\title{
A PAlavra COMO OBJETO DE valor POETICo EM GaRCia MARQUEZ *
}

\author{
Cella Martins Seabra *
}

\section{Palavra poétlca e mito}

O objetivo destas notas, a partir da análise do conto de Gabriel Garcia Marquez El ahogado más hermoso del mundo 1 foi o estabelecimento de elementos que possibilitem uma leitura do texto fantástico. Sem de nenhuma maneira ter a pretensão de propôr um modelo para essa leitura, que, por sua própria natureza, repudia os modelos, estas notas tentaram tecer comentários que sugerissem, no âmbito da literatura fantástica, as ligações entre o texto literário e o mito. A sua pergunta fundamental foi qual a função de um elemento fantástico introduzido no interior de uma narrativa como a exemplificada pelo conto "El ahogado más hermoso del mundo". A primeira resposta que se impôs foi a que a introduçāo de um elemento fantástico leva à reversão da realidade e incorporando-se a ela atira-lhe nova luz, motivando c questionamento dos valores estabelecidos. A oposição de valores gerada pela intromissão fantástica é percebida ao nível da linguagem, que se vê enriquecida em virtude das novas acepções que adquire, tornando-se plurisignificativa. Apagados os limites entre real e irreal, entre senso e não-senso, a palavra abre-se ao sentido multifacetado que leva ao conhecimento mais profundo da realidade. A palavra, em sua função poética, torna-se um meio de conhecimento ao expressar aquilo que escapa à delimitação dos fatos c à concepção do real como apenas concreto. E evidente que a obra de arte não pode ser reduzida a seu material "concreto", mas que possui um sentido que se coloca além do referente objetivo (quer seja um fato, um cbjeto, etc.). A obra de arte constitui por si mesma um elemento de mediação de diferentes universos: o das coisas e o das palavras, o do indivíduo e o da coletividade. Por isso, como meio de conhecimento, ela se aproxima do mito cujo objeto são as realidades não-formalizáveis de um contexto-limite que escapa ao esforço de expressão e se coloca ao nível do aconte-

- Celia Martins Seabra. Licenciada em Letras pela Universidade Católica de Petrópolis onde leciona Literatura Brasileira e Prática de Ensino de Literatura. Mestranda em Poética na Faculdade de Letras da Universidade Federal do Rio de Janeiro.

- Trabalho final apresentado no segundo semestre de 1974 à Professora Bella Jozef no curso A estrutura do fantástico e que obteve conceito A. 
cimento (ou seja, das possibilidades virtuais múltiplas). Num esforço de conhecimento totalizador, a obra de arte busca o mito como realidade geradora, incorporando à sua estruturação suas virtualidades inesgotáveis que revertem sobre si mesmas, num constante movimento circular em que o objeto é o meio que jamais revela e cujo valor está nesse irrevelado sempre presente que escapa a categorizaçāo espaço-temporal.

Principalmente no que se refere à obra fantástica parece haver um esforço reiterado de busca das fontes miticas, em que o conceito de realidade amplia-se numa substituiçāo constante do anteriormente formulado. Assim, no conto "El ahogado más hermoso del mundo" temos esse jogo de substi1uiçōes em todos os niveis: o cotidiano pelo mítico, o crónos pelo aîn, o real pelo ideal, o individual pelo coletivo, onde cada um nāo leva à negaçāo dc anterior, mas a um aprofundamento em que mito e realidade fundem-se pela palavra que representa, em sua riqueza conotativa, a capacidade de renovação da vida, expressa pelo mito do Eterno Retorno: eterno retorno das forças vitais, eterno remeter-se a si mesma da imagem poética, inesgotável como a esséncia do ser. Por isso, pode a nova face do real ser repetida ao infinito, "en catorce idiomas", em dimensões múltiplas que constituem uma nova ordem incomensurável do cosmos material, o reino da liberdade, e do cosmos artístico, o rcino da criação.

\section{2. "El ahogado más hermoso del mundo"}

Este conto construído sobre uma matriz de parábola propõe uma leitura em três niveis fundamentais:

a) o nivel do cotidiano (uma pequena comunidade encontra um afogado cesconhecido e toma providências para o seu enterro);

b) o nivel do comportamento (reaçōes da população em relaçāo ao morto); c) o nível simbólico (os possíveis significados criados a partir do aparecimento de Esteban).

Cada um desses niveis estrutura-se em très etapas (encontro, especüaÇāo, reconhecimento) e interpenetram-se de maneira que a realidade cotidiana gera o comportamento e ambos carregam o significado simbólico. Quanto aos elementos em que se baseia a construçāo do conto, temos:

\subsection{Tempo e espaço}

O tempo real é o tempo da narrativa, expresso através de verbos e expressōes que indicam a progressão temporal (después cuando, etc.). 0 tempo da açāo exterior desenvolve-se paralelamente ao da açāo interior em nivel imaginário. Assim, as mulheres, enquanto cosem roupas para o morto, especulam sobre ele, caracterizando-o em oposiçāo do real conhecido. Ambos os tempos caminham simultâneos e alargam-se à intemporalidade, ou seja, ac tempo mítico que resulta do tom onírico e do sentido parabólico que o conto adquire em seu desenrolar. O processo de criação do espaço apresenta 
as mesmas caracteristicas: paralelo ao espaço real (a aldeia à beira-mar sobre os penhascos) constrói-se o espaço mítico, alargado à sua dimensão simbólica. Do espaço anteriormente nāo caracterizado, mas apresentado como um lugar comum, emerge o espaço virtual para onde apontam todas as direções. Por ele perde-se o rumo inicial por imposição do rumo absoluto.

"Algunos marineros que oyeron el llanto a la distancia perdieron el rumbo $[\ldots] "$ " (p. 55).

[...] y el capitán tuviera que bajar de su alcazar con su uniforme de gala, con su atrolabio, su estrella polar y su ristre de medalla de guerra, y señalando al promontorio de rosas en el horizonte del Caribe dijera en catorce idiomas, miren allá, donde el viento es ahora tan manso que se queda a dormir debajo de las camas, allá, donde el sol brilla tanto que no saben hacia donde girar los girasoles, si allá, es el pueblo de Esteban. (p. 56).

Este espaço absoluto, fruto de uma consciência superior, relaciona-se à função orientadora do mito que estabelece bases estético-éticas para que o homem compreenda e assimile os dados de sua experiência. Este espaço alargado é a representaçāo do valor de orientação do mito que, penetrando em rcgiōes cada vez mais amplas, estabelece, sem fixidez, pontos e horizontes que compensam o ser humano em sua falta de direçāo original em meio a uma realidade multivalente e frequentemente hostil.

\subsection{Núcleos significativos}

\subsubsection{A água}

O primeiro núcleo conotativo prende-se à água, que nos aparece em duas formas opostas:

\subsubsection{O mar}

Considerado em sua acepção mais profunda de caos primordial, de um lado fonte de vida "Pero el mar era manso y pródigo, y todos los hombres cabían en siete botes. [...]" (p. 50) e de outro, lugar impenetrável e misterioso cujos segredos encontram-se muito além da imaginação, "[...] su vegetacion era de oceanos remotos y de águas profundas, [...]" (p. 50) este arquétipo trás em si o dinamismo do eterno fluir. E a representação do movimento perpétuo que produz a vida em oposição aos penhascos estáticos e imutáveis. Sendo fonte de vida, é ele que lança a semente (o afogado) aos penhascos (terra-elemento fixo) para fecundá-los. O seu ritmo é a representaçāo do ritmo cósmico, pois é a partir do caos, por intermédio do ritmo, que se estabelece a ordem cósmica. Assim, é o movimento rítmico do mar, caos não diferenciado, que traz à realidade o elemento instaurador de um novo cosmos pelo rompimento da Inércia.

\subsubsection{O rio}

Usada em oposição ao mar, a imagem do rio prende-se à sua comparaçāo arquetípica com a vida humana. O mar ć a fonte primeira; o rio é a indi- 
viduaçāo de força que vai ter à fonte para nela se fundir. Sendo, porém, o simbolo da existência de cada indivíduo em particular está diretamente ligado às idéias de matéria e de fugacidade. Por isso, o afogado que provém do mar é mais digno, por não ter "la catadura sórdida e menesterosa de los chogados fluviales", ou seja, não pertencer ao grupo daqueles que se deixam levar pelo rio material da vida. Esta comparação já é um indício da ratureza especial que será conferida ao afogado no desenrolar da narrativa.

\subsubsection{0 povo}

O povo nos é apresentado em progressão etária o que leva à progressão do reconhecimento do ideal representado por Esteban. Primeiro temos as crianças que por sua inexperiência não o reconhecem, ou melhor, confundem-no com coisas diversas "Los primeros Niños que vieron al promotorio oscuro y sigiloso que se acercaba por el mar, se hicieron la ilusión de que cra un barco enemigo. Después vieron que no llevaba banderas ni arboladura. y pensaron que fuero una ballena $[\ldots]^{\prime \prime}$ (p. 49) o que os leva a uma atitude espontánea e irreverente "Habian jugado con él toda la parte, enterrandolo y desenterrándolo en la arena, [...], (p. 49).

A seguir, os homens que o encontram, mas que apesar da perplexidade inicial mantem-se no nível objefivo concreto "Los hombres que lo cargaron hasta la casa más próxima notaron que pesaba más que todos los muertos conocidos". (p. 49).

Sāo as mulheres que começam o seu verdadeiro reconhecimento (por se encontrarem mais próximas do morto, quer objetivamente, quer por se$1 \mathrm{~cm}$ elas mesmas fontes de vida), que se inicia pelo impacto emocional produzido pelo morto "Fascinadas por su desproporción y su hermosura [...] (p. 51) que se impõe gradativamente, influindo mesmo no meio ambiente “[...] les parecia que el viento no había sido nunca tan tenaz ni el Caribe rabía estado nunca tan ansioso como aquelle noche, y suponian que esos cambios tenían algo que ver con el muerto, [...]" (p. 51) atć à revelação. inicialmente percebida pela mulher mais velha, a mais experiente e a menos envolvida cmocionalmente pelo afogado: “[...] cuando la más vieja de las mujeres, que por ser la más vieja había contemplado el ahogado con menos pasión que compasión, suspiró: - Tiene cara de llamarse Esteban". (p. 52).

O nomear é a forma mais óbvia de reconhecimento, pois o dar nome é estabelecer relācoões objetivas, é atribuir significações que se tornam coletivas: "Era verdad. A la mayoria le bastó con mirarlo otra vez para compreender que no podia tener otro nombre. [...]" (p. 52).

Este primeiro nível de revelação traz em si duas atitudes opostas a) o encarecimento de valores, resumo da visão idealista: "[...] Pensaban que si aquel hombre magnífico hubiera vivido en el pueblo, su casa habría tenido las puertas más anchas, el teto más alto y el piso más firme, y el bastidor de su cama habría sido de cuardenas maestras con pernos de hierro y su mujer habria sido la más feliz. $[\ldots]^{n}$ (p. 51) que se constrói através da 
adjetivação e dos advérbios de intensidade (magnífico, más anchas, más alto. más firme, más feliz, etc.) e intensifica-se pela comparação com a realidade cotidiana

... Lo compararon en secreto con sus própios hombres, pensando que no serian capaces de hacer en toda una vida lo que aquél era capaz de hacer en una noche, y terminaron por repudiarlos en el fondo de sus corazones como los seres más escuálidos y mezquinos de la tierra... (p. 51).

b) a inversão de valores, resumo da visão materialista, depreciação contínua dos elementos antes encarecidos, o que assinala o deslocamento da grandeza nāo compreendida, expressa pela justaposiçāo de adjetivos em "bobo grande", "tonto hermoso". Essa alternância ideal - real possivel conduz ao segundo impacto emocional ocasionado pela destruição da visão ideal.

Más tarde, cuando le taparon la cara con un pañuelo para que no le molestara la luz, lo vieron $\tan$ muerto para siempre, tan indefenso, tan parecido a sus hombres, que se les abrieron las primeras grietas de lágrimas en el corazón. (p. 53).

Ainda aqui mantem-se a diferença etária como reveladora das reaçōes humanas: "Fué una de las más jóvenes la que empezó a sollozar [...]" (p. 53) i que por sua menor experiência era mais vulnerável à destruição dos fdolos e das ilusōes. A volta dos homens da aldeia concretiza a depreciação suspeitada pelas mulheres em plano mental. A sua atitude revela o desejo de libertaçāo de algo cuja simples presença incomoda por ser a evidência clara de uma realidade além da mesquinhez cotidiana. Os homens da aldeia veem-se assaltados por temores de ver ruir sob o peso de um ideal mais alto as suas regras estabelecidas. Elemento estranho à ordem estagnada. Esteban é a possibilidade de transgressāo. Veículo de um valor desconhecido e repudiado pelo comodismo estéril, a sua presença supõe o olhar de frente, supōe o exame, a mirada ao espelho implacável. Nos homens os movimentos de raiva contra Esteban sāo reflexos de seu medo interior. Esteban representa um perigo como núcleo gerador de uma nova luz que atirada sobre o cotidiano revelará sua estreiteza e pobreza “[...] los que sentían amargas las minuciosas noches del mar temiendo que sus mujeres se cansaron de soñar con ellos para soñar con los ahogados [...]" (p. 55).

A segunda revelação (aos homens) vem reiterar $e$ intensificar os valores ideais. "Era Esteban. No hubo que repetirlo para que lo reconocieran". (p. 54) pois leva, primeira a uma comunhão integrada de esforços: "Fué así como le hicieron los funerales más espléndidos que podían concebirse para un ahogado expósito [...]" (p. 55) a seguir, a uma ampliação gradativa da visão ideal que funciona como um clemento de ligação, de fusăo coletiva

[...] A última hora les dolió devolverlo huérfano a las águas, y le eligieron un padre y una madre entre los mejores, y otros se le hicieron hermanos, tios y primos, así que a través de él todos los habitantes del pueblo terminaron por ser parientes entre sí. [...] (p. 55) 
c termina na transfiguração da realidade enriquecida após a visão reveladori provocada pelo ideal:

No tuvieron neccssidad de mirarse los unos a los otros para darse cuenta de que ya no esteban completos, ni volverían a estarlo jamás. Pero también sabían que todo sería diferente desde entonces, que sus casas iban a tener las puertas más anchas, los techos más altos. los pisos más firmes, para que el recuerdo de Esteban pudiera andar por todas las partes sin tropczar con los travesños. y que nadie se atraviera a susurrar en el futuro ya murió el bobo grande, qué lástima, ya murió el tonto hermoso, porque ellos iban a pintar las fachadas de colores alegres para eternizar la memoria de Esteban, y se iban a romper el espinazo excavando manantiales en las piedras y sembrando flores en los acantillados, para que en los amaneceres de los años venturos los pasajeros de los grandes barcos despertaran sofocados por un olor de jardines en alta$\operatorname{mar}[\ldots](p .56)$.

Esteban. o morto cuja presença c contemplação introduz a transgressāo c a perda dos limites pela consciência dos próprios limites, permite ao povo - aflorar da esséncia do ser que sāo: semelhantes, "parientes entre si", por Luma mesma raiz de que Esteban é a afirmação e a denúncia: depois de seu conhecimento a ordem já nāo poderá ser a mesma, mas a outra, mesma enriquecida pela volta à fonte c pela incorporaçāo das potências do fundo.

\subsubsection{Esteban}

O afogado, núcleo central do conto, resume em si a fusão vida-morte. $O$ seu aspecto incial $\hat{e}$ o do afastamento em relaçāo ao povo: ele está morto e é um morto desconhecido. "[...] notaron que su vegetación era de oceanos remotos y de águas profundas [...]" (p. 50).

A imagem "morte" inicial É negada pelo seu crescimento, ou seja, o ideal aresar de morto aparentemente (afogado pelo real) mantém a sua força vital latente. "[...] pensaron que tal vez la facultad de seguir creciendo después de la muerte estaba en la naturaleza de ciertos ahogados. [...]" (p. 49) ropresentada pelo clemento aquático vitalizador de que ele se encontra impregnado, "[...] el água se le había metido dentro de los huesos" (p. 49).

A caracterização do afogado em termos concretos reverte a qualidades abstratas:

a) tamanho físico:

[ ..] No sólo era el más alto, el más fuerte, el más viril y el mejor ermado que habian visto jamás, sino que todavia cuando lo estaban viendo no les cabia en la imaginación [...] (p. 50,

transforma-se em força moral, em capacidade de realização 


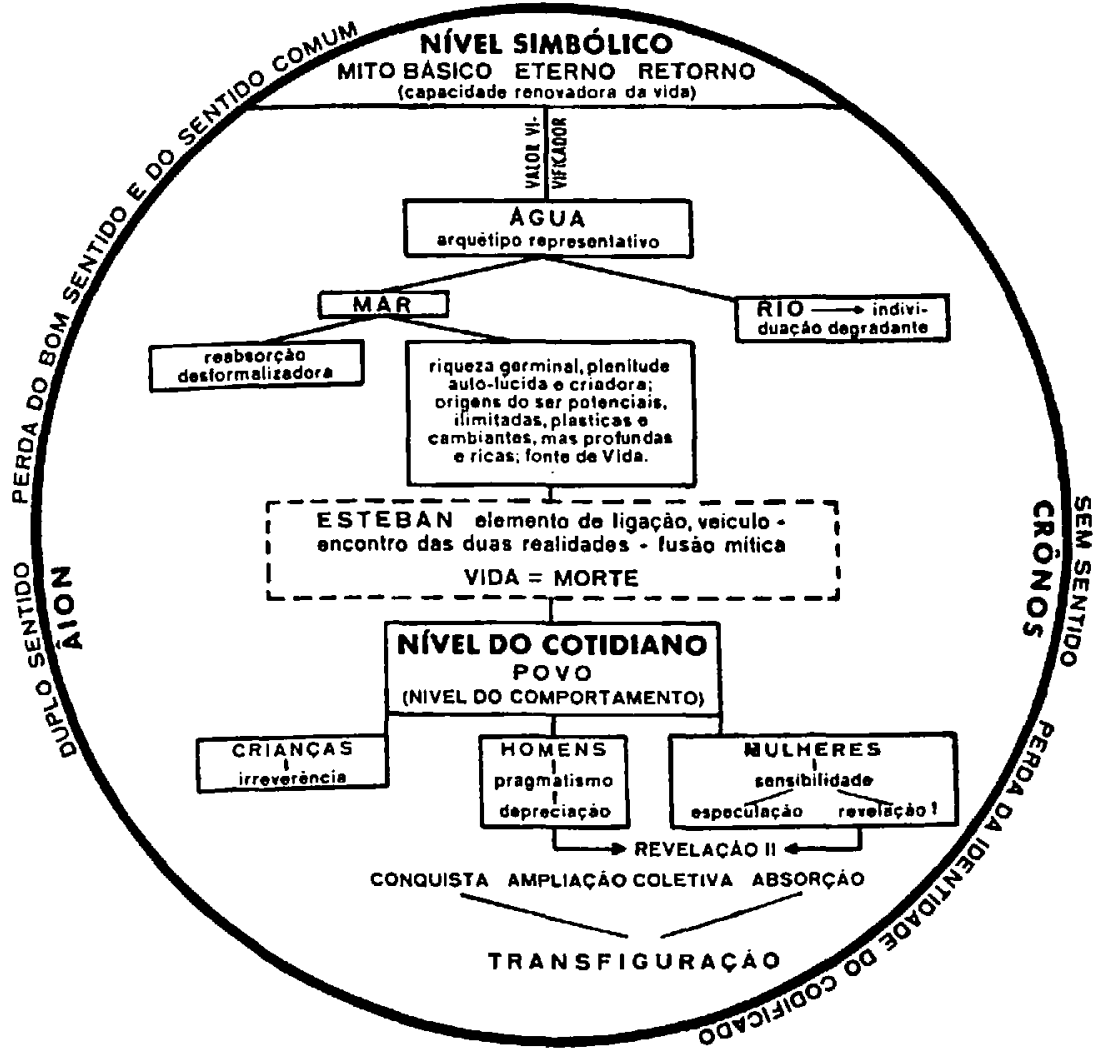


... Pensaban que habría tenido tanta autoridad que hubiera sacado los peces del mar con sólo llamarlos por sus nombres, y habria puesto tanto empeño en el trabajo que hubiera hecho brotar manantiales de entre las piedras más áridas y hubiera podido sembrar flores en los acantillados. [...] (p. 51)

b) beleza física, em poder de transfiguração, de reversão dos critérios estabelecidos, de "impressão" de sua beleza ao meio ambiente, como acontece com a aldeia a que foi dar. Antes de seu aparecimento ela nos é descrita como árida, agreste, sem colorido, hostil:

[...$]$ El pueblo tenía apenas unas veinte casas de tablas con pátios de piedras sin flores, desperdigadas en el extremo de um cabo desértico [...] (p. 50)

e depois, transformada em um espaço mítico-simbólico

[. .] ellos iban a pintar las fachadas de colores alegres para eternizar la memoria de Esteban, y se iban a romper el espinazo excavando manantiales en las piedras y sembrando flores en los acantilados, para que en los amaneceres de los años venturosos los pasajeros de los grandes barcos despertaran sofocados por un olor de jardines en altamar $[\ldots]$ (p. 56)

c) capacidade de auto-superaçāo: apesar de escarnecido e sentindo-se deslocado ele continua sorrindo, provando que se encontra acima dos condicionamentos materiais.

[...] Lo vieron condenado en vida a pasar de medio lado por las puertas, a descalabrarse en los travesaños, a permanecer de pie en las visitas sin saber qué hacer con sus tiernas y rosadas manos de buey de mar, mientras la dueña de casa buscaba la silla más resistente y le suplicaba muerta de miedo siéntese aquí Esteban, hágame el favor, y. él recostado contra las paredes, sonriendo, no se preocupe señora, así estoy bien, con los talones en carne viva y las espaldas escaldadas de tanto repetir lo mismo en todas las visitas [...] (p. 52)

Mesmo a morte, a prova suprema, ele “... sobrellevaba con altivez".

d) humildade, que consiste na não-imposiçāo de sua presença, no respeito à liberdade de escolha dos que o cercam, numa doação muda. sem nada exigir:

[.. ] Bastó con que le quitaron el pañuelo de la cara para darse cuenta de que estaba avergonzado, de que no tenia la culpa de ser tan grande, ni tan pesado ni tan hermoso, y si hubiera sabido que aquello iba a suceder habría buscado un lugar más discreto para ahogarse, en serio, me hubiera yo mismo amarrado un áncora de galeón en el cuello y hubiera trastabillado como quien no quiere la cosa en los acantillados, para no andar ahora estorbando con este muerto de miércoles, como ustedes, dicen para no molestar nadie con esta porqueria de fiambre que no tiene nada que ver conmigo. (p. 55). 
A presença do morto Esteban, é a denúncia da morte dos vivos. E o despertar da consciência para o absurdo do cotidiano estreito e para o sentido da perda de uma beleza superior. Esteban é a concretização dessa beleza que é deixada à deriva e encontra-se coberta pela lama do cotidiano (aqui, os destroços marinhos que representam o dia a dia da aldeia), e que de tal maneira se tornou estranha que toda tentativa para acomodá-la ao real, ou seja, vesti-la com as roupas comuns resulta em fracasso: “[...] Pero fué una illusión vana. El lienzo resultó escaso, los pantalones mal cortados y peor cosidos le quedaron estrechos, y las fuerzas ocultas de su corazón hacian saltar los botones de la camisa $[\ldots]^{n}$ (p. 52).

Esteban é semente. Do caos primordial (o mar desconhecido e profundo, fonte de vida) ele provem para gerar o cosmos (as flores, os girassóis, a aldeia de Esteban); está morto, (afogado) como semente para libertar a sua potência interior que irá florescer na aldeia de Esteban. Morte e vida nele se encontram e nele perdem seus limites opositivos. Por ele o aparentemente vivo resulta morto e o morto, fonte de vida, numa representação do círculo vital começo-fim-começo. em que o encontro de Esteban prova nāo ser um encontro, mas um re-encontro das forças vitais.

Esta imagem circular centrada em Esteban repete-se ao longo da construção do conto no círculo religioso das mulheres que velam o morto, " $[\ldots]$ Mientras cosían sentadas en círculo, contemplando el cadáver entre puntada y puntada [...] (p. 51) no círculo temporal: Esteban é encontrado nco amanhecer e a narração estende-se até o outro amanhecer; no sol absoluto : nos girassóis, circulos perfeitos e intemporais " $[\ldots]$ el sol brilla tanto que no saben hacia donde girar los girasoles [...]" (p. 56) e, finalmente, na própria estrutura circular fechada que começa com o recolhimento do afogado no mar e termina com sua devolução às águas, final de começo implícito em sua intemporalidade, uma vez que "[...] Lo soltaron sin ancla para que volviera si queria, y cuando quisiera. y todos retuvieran al aliento durante la fracción de siglos que demoró la caída del cuerpo hasta el abismo $[\ldots]^{\prime \prime}$ (p. 56).

\subsubsection{O fogo e o caráter messiânico}

A figura de Esteban relaciona-se com outro elemento primordial: o fogo. A primeira referência a seu caráter igneo faz-se através de sua relaçăo com a palavra, que pertence ao campo igneo e solar. A palavra possui funçāo civilizadora e iluminante e constitui um complemento das potencialidades vitais da água. Assim no 1. Capitulo do Gênesis é o Verbo (Logos) que ordena o caos, criando a luz:

“1. No começo criou Deus o céu e a terra.

2. A terra, porém, era solidāo e caos. informe e vazia; as trevas cobriam o abismo, mas o espírito de Deus pairava sobre as águas.

3. Disse Deus: "Haja luz". E houve luz". 
e no prólogo do IV Evangelho, a palavra é apresentada com a funçāo de "iluminar a todo homem que vem a este mundo". (Joāo 1,9). Além disso, a Falavra possui tradicionalmente o poder mágico de posse, por isso Esteban seria capaz de tirar "los peces del mar con sólo llamarlos por sus nombres" $e$ as mulheres que o nomeiam e iniciam o seu reconhecimento o sentem como coisa sua, uma vez que ninguém o reclama pelo nome: "- Bendito sea Diós - suspiraron -: es nuestro!" (p. 53)

Sendo Esteban um elemento auto-referente, ele $\boldsymbol{e}$ nomeado "Era Estehan $[\ldots]$ " e nomeia " $[\ldots]$ es el pueblo de Esteban $[\ldots] "$ (p. 52) conferindo à aldeia suas qualidades de iluminação " $[\ldots]$ el sol brilla tanto que no saben hacia donde girar los girasoles [...] (p. 56).

o próprio nome Esteban carrega em si propriedades criadoras, pois ceriva do latim "stipa"/esteva, variedade de colmo cuja palha (isto é, depois de morto) é utilizada, quer como cobertura de cabanas (como protetor), quer como fertilizador dos campos, pois junto à terra transforma-se no húmus que possibilita a plantação e a germinação das sementes.

O outro aspecto ígneo e solar encarnado por Esteban refere-se a sua funçāo messiânica (o Messias é o portador de uma nova luz e uma nova ordem). O seu caráter messiânico explicita-se pela alusāo a outros enviados divinos ou heróis semidivinos: a) Moisés (o salvo das águas, deixado a boiar numa cesta de junco), que podia fazer brotar água das pedras do deserto. "[...] y habría puesto tanto empeño en el trabajo que hubiera hecho brotar manantiales de entre las piedras más áridas [...]" (p. 51) alusão simbólica. segundo a tradição israelita, em que a água é o símbolo da vida e da ação vivificante de Deus: o homem e o povo prosperam por estarem junto ao mar e o milagre de uma nova vida espiritual expressa-se pelos mananciais que manam no deserto. b) Jonas e Ulisses que representam o mito da morte que leva ao renascimento, expresso, em relação ao primeiro, pelo ser devorado por um monstro "[ ...] pensaron que fuera uma ballena [...]" (p. 49), e, ao segundo, pela viagem noturna por um mar ignoto, cheio de perigos (referência ao mito das sereias) " $[. .$.$] Algunos marineros que oyeron el llanto a la$ distancia perdieron la certeza del rumo, y se supo que se hizo amarrar al palo mayor, recordando antiguas fábulas de sirenas. $[\ldots]^{n}$ (p. 55).

c) Nóe, elemento gerador de uma nova raça após o Dilúvio, aqui representado pelo barco "[...] se hicieron la illusión de que era un barco enemigo". (p. 49) sem mastros ou bandeiras, possível associação com a arca bíblica e com os mitos americanos que colocam o Sol ou o herói civilizador de caráter solar como viajante de um barco em que a madeira serve de mediação entre as águas primordiais e o fogo vivificador.

d) Estevão, o homônimo bíblico da personagem do conto, um dos sete diáconos eleitos pelos apóstolos para manter a ordem em Jerusalém, aquele que "cheio de graça e poder fazia grandes prodígios e milagres entre $o$ 
povo" (At. 6, 8) e cujo "semblante parecia o de um anjo" (At. 6, 15) contra quem blasfemaram os nomens de Jerusalém.

e) Cristo, o Redentor: as relaçōes podem ser encontradas desde o cenário tempestuoso, que se assemelha ao da Crucificação, inclusive com o efeito pacificador que o Messias possuía; aqui, por causa de Esteban "[...] el viento es ahora tan manso que se queda a dormir debajo de las camas [...] (p. 56) até ao sofrimento imposto pela ordem mesquinha dos homens "[...] y él recostado contra las paredes, sonriendo, no se preocupe, señora, asi estoy bien, con los talones en carne viva y las espaldas escaldadas de tanto repetir lo mismo en todas las visitas [...] (p. 52) e o poder de superaçāo desse sofrimento; pelo ser escarnecido e insultado pelos homens “ $[\ldots]$ los hombres acabaron por despotricar que de cuándo acá semejante alboroto por un muerto de garrote un ahogado de nadie, un fiambre de mierda $[\ldots] "$ (p. 54), e. finalmente, por sua permanência e ressurreiçāo como nova ordem vital, expressa pela transfiguraçâo da realidade e pelas flores, os girassóis, flor solar, que se relacionam à rosa mística bíblica e ao lótus bramânico (que representa a consciência espiritual que nasce no lodo e floresce na luz) de onde renasce a força vital (Bhraman) no começo de cada Kalpa (cosmos revivido) e que constitui o centro de Vishnu ( o ordenador e preservador do universo).

\subsubsection{Simbolismo numerérico}

\subsubsection{O número vinte}

"[...] El pueblo tenía apenas unas veinte casas de tablas, con piedras sin flores, desperdigadas en el extremo de un cabo desértico. [... $]^{\prime \prime}$ p. 50.

0 vinte è o número da vida e do impulso (representado por Esteban), dos obstáculos e dos embaraços (a atitude depreciativa dos homens em relação ao morto), das decisões (o unir-se e mudar seu modo de vida por influência da figura de Esteban) e da exaltação (a transfiguração da realidade e a exaltação dos valores ideais provenientes de Esteban). E o número ciue representa a ascenção do homem ao conhecimento da liberdade espiritual, quando as sombras do materialismo somem de seus olhos e ele desperta para uma nova ordem. O scu simbolismo expressa-se por uma mulher, um homem c uma criança que se levantam de um túmulo, como todo o povo da aldeia que desperta para uma nova vida além de sua terra deserta.

\subsubsection{O número sete}

"Pero el mar era manso y pródigo, y todos los kumbres cabían en siete botes [...]" (p. 50).

O sete é um número inteiramente religioso e representa o triunfo do espirito sobre a matéria. Segundo os pitagóricos, é o novo príncipio de fecundidade. E o superar quase transcendente de equilibrio $e$ dá acesso a uma nova dimensão, a uma nova esfera, realmente virginal. Este qualificativo 
virginal pode ser remetido ao cenário escolhido para o conto, o Caribe, cuja natureza paradisíaca exprime a posiçāo do autor em se colocar em busca de outro contexto que melhor retrate a realidade americana, ou o sentir americano devolvendo-lhe a força inexplorada de sua mitologia. $O$ sete constitui a expressão numérica do tempo purificado, reintegrado à potência das origens. Assim, os "siete botes" relacionam-se ao resultado da transfiguraçāo realizada por Esteban (cujo homônimo bíbliıo é um dos sete diáconos). Se o vinte é a ascensão à liberdade espiritual, o sete ś essa mesma liberdade, a superaçäo da matéria pela ação vivificadora do espírito. Além disso, ambos os números estão relacionados à Lua (o sétimo planeta dos antigos) e a Lua, uo mar (pelo controle das marés) e à fertilidade constantemente renovada.

\subsubsection{O número quatorze}

“[...] y el capitán tuviera que bajar de su álcázar con su uniforme de gala, con su astrolábio. su estrella polar y su ristra de medallas de guerra, y. señalando el promontorio de rosas en el horizonte del Caribe dijera en catorce idiomas, miren allá, [...]" (p. 56).

Número do movimento eterno e da combinaçāo, representativo da revolução, do movimento e da energia, o número quatorze complementa as idéias sigeridas pelo vinte e pelo sete. Nele a luta da matéria tem seu início, por ele torna-se possivel a multiplicidade dos caminhos $\mathrm{e}$ da linguagem. Ligado ao simbolismo do fogo a um só tempo sugere a competição e a luta, entendimento e o poder, o prazer e a especulação. Apontar a realidade transcendente do povoado de Esteban, nomeá-lo em "catorce idiomas" é afirmá-lo como c ponto de convergência das forças opostas, o centro neutro em que o passivo e o ativo se encontram (os homens $e$ as mulheres dedicados a uma tarefa conjunta), em que a vida e a morte provam nāo ser uma a negação da outra. em que o sofrimento torna-se a condição para o prazer.

\subsection{5 o sofrimento e o labirinto}

Mais dois núcleos podem aqui ser tratados numa intensificação da atmosfera mitica que perpassa o conto. Um se refere ao sofrimento como caminho para um conhecimento mais pleno da realidade. Sob este aspecto ele $e$ representado pelas mulheres que lamentam o morto, o que lhe confere uma jóentidade cada vez mais densa: "[...] se les abrieron las primeras grietas de lágrimas en el corazón. Fué una de las más jóvenes la que empezó a sollozar. Las otras alentándose entre si, pasaron, de los suspiros a los lamentos, y mientras más sollozaban más deseos sentian de llorar, porque el ahogado se les iba volviendo cada vez más Esteban [...]" (p. 53).

o sofrimento apresenta-se ainda como sacrifício, condição indispensável para o aperfeiçoamento e a transcendência: " $[\ldots]$ y se iban a romper el espinazo excavando manantiales en las piedras y sembrando flores en los acantillados para que en los amaneceres de los años venturos los pasajeros 
de los grandes barcos despertaran sofocados por un olor de jardines en altamar. [...] (p. 56).

Outra imagem é a labirinto que traz em si sugestōes de perda, de falta de direçāo e relaciona-se diretamente com a vida humana sem rumo ou de rumo desconhecido. Assim, temos Esteban, o ideal abandonado e ainda não reconhecido "[...] sus ropas estaban en piltrafas, como si hubiera navegado entre laberintos de corales [...] (p. 50).

Depois, as mulheres cuja visão de Esteban ainda não é total e cujo reconhecimento ainda nāo se impôs: "[...] Andaban extraviadas por esos cédalos de fantasia [...]" (p. 51) e, também os homens, antes da revelação da verdadeira natureza do afogado:

... Cansados de las averiguaciones tortuosas de la noche, lo único que querian era quitarse de una vez el estorbo del intruso antes de que prendiera el sol bravo de aquél dia árido y sin viento. (p. 53).

\section{O valor da linguagem poetica}

O valor da linguagem poética está essencialmente em sua riqueza de sentido que leva à possibilidade de estabelecimento de um sentido além do imediato. No "afogado" ¿ a linguagem que estabelece além do cotidiano (sempre mantido no desenrolar do conto) o sentido mítico que transcende o cotidiano para questioná-lo e se sobrepor a ele. O texto é o espaço que possibilita a configuração da utopia, a utopia propulsora, horizonte sempre fora do alcance e, por isso. sempre desejado. Objetivo que atrai, o espaço utópico é a razão da busca e de todo movimento. Evitando a estagnação e o acomodamento, a utopia acena com as probabilidades de recuperação da essência do ser em si. Sem um modelo fixo, ela é o ponto de apoio para o questionamento dos modelos, é o além-limite que mantém frente à realidade a posição nāo redutível ao sistema. Imagem da falha, afirmaçāo do que falta, a utopia força a realidade a se olhar a si mesma, a mergulhar em si à procura das respostas para as perguntas que jazem silenciosas em meio às malhas da rede "afogadas" pelas soluçōes imediatistas e utilitárias, omissas da totalidade. A renovação faz-se, no texto, e é apreendida através das palavras cuja ambiguidade espelha a relatividade dos conceitos estabelecidos. Os limites atenuam-se e cria-se a possibilidade de transiçāo livre de um nível a outro (cotidiano, comportamente, mítico) o que permite a intersecção das qualidades próprias a cada nível. Assim. o mítico substitui o cotidiano e transforma-se nele por ação do comportamento. O sobre-humano (Esteban) revela ao humano (o povo) a sua condiçāo sub-humana, despertando-o. Isto carrega a idéia de que o homem possui todas as capacidades renovadoras em latência, que se manifestam após uma tomada de consciência auto lúcida, fruto de uma escolha 
[...] Mientras se disputaban el privilegio de llevarlo en hombros por la pendiente escarpada de los acantillados, hombres y mujeres tuvieron conciencia por primeira vez de la desolación de sus calles, la aridez de sus patios, la estrechež de sus sueños, frente al esplendor y la hermosura de su ahogado. [...] (p. 56).

A escolha entre o real e o ideal, o Bem e o Mal, geradora de um sentido diverso e de uma orientação diversa para a existência pode propor, inclusive. scgundo Gilles Deleuzes. 1 um vínculo intimo entre a teoria do sentido e a etica. $O$ despertar estruturado pela linguagem reverte sobre ela mesma, num enriquecimento significativo em que a palavra transcende sua denotaçāo codificada e desgastada pelo uso para adquirir a força de um prisma de muitas lácetas em que nenhuma realidade é só ela mesma, mas um ângulo parcial de uma realidade maior. A mediação efetuada pela linguagem entre o nível objetivo e o mítico confere à obra fantástica as potencialidades do paradoxo, que para Gilles Deleuzes, 2 é a inversão simultânea do bom sentido e do sentido comum: por uma parte aparecendo como o duplo sentido (afogado - morte aparente/vida essencial); por outra, como o sem-sentido da identidade perdida (o codificado para afogado dilui-se no contexto). Além disso é a linguagem que formaliza os conteúdos informalizáveis do mito; mas sua ação formalizadora faz-se com a permanência da multidimensionalidade mítica que ¿ ponto de partida e de confluência de todas as dimensōes essenciais do mundo, numa circularidade aberta que se reatualiza constantemente numa proliferação indefinida de sentido. Concluindo, poder-se-ia propor que a obra fantástica coloca-se em relação a uma concepção totalizadora do real que reincorpora os valores do mito, considerado, não como uma criação arbitrária da fantasia, mas como diz K. Rahner, 3 parte do "existencial subrenatural" cio homem, presença ausente da plenitude radical que emerge a cada instante, sempre renovada.

\section{REFERENGIAS BIBLIOGRAFICAS}

CENCILIO, Luis. Mito; semántica y realidad. Madrid, Ed. Catolica, 1970. 453 p. DELEUZE, Gilles. Logica del sentido. Barcelona, S. Barral, 1971. 430 p.

GARCIA MARQUEZ, G. El ahogado más hermoso del mundo. In:

La increble y triste historia de la Cándída Erendira $y$ de su abuela desalmada.

Buenos Aires, Sudamerlcana, 1972. p. 11-20.

KOZMINSKY, Isidore. Números; magła e mistério. Săo Paulo, Ed. Tres 1973. $163 \mathrm{p}$.

LELCO Universal. Porto, Lello, s.d. v. 1.

\section{Resumo}

Este trabalho tem como objetivo principal a proposição de uma leitura de texto fantástico. Apoiado na análise do conto de G. Garcia Marquez "El

1 DELEUZE, Gilles. Lóglca del sentido. Barcelona, Seix Barral, 1071, p. 47.

2 Ibidem, p. 106.

3 Rahner, K. Apud CENCILLO, Luis. Mito; semántica y realidad. Madrid, Ed. Catolica, 1970, p. 452. 
ahogado más hermoso del mundo" procurou apontar as relaçōes entre a literatura e o mito, sublinhando a multidimensionalidade do sentido adquirida rela linguagem quando em funçāo poćtica. Nesta leitura não nos propusemos a formular um conceito do "fantástico", mas antes observar os efeitos por elc produzidos em nossa percepção do real e o questionamento de valores que dai nos adveio, questionamento esse que, parece-nos, encontra-se na raiz mesma da obra de arte.

\section{Summary}

This work has, as its principal aim, the proposal of a reading to the so-called fantastic text. Based on the analysis of $G$. Garcia Marquez "El ahogado más hermoso del mundo" it tried to point out the relationship between literature and myth, underlining the multiple dimensions acquired by lan£uage when in its poetic function. In this reading we did not propose ourselves to give a concept of the "fantastic", but to observe the effects it produces on r.ur perception of reality and the questions on values that appear from a new point of view, questions that seem to us to be strictly connected to the origin of the work of art itself. 